\title{
Respiratory muscle endurance is limited by lower ventilatory efficiency in post-myocardial infarction patients
}

\author{
Laura M. T. Neves, Marlus Karsten, Victor R. Neves, \\ Thomas Beltrame, Audrey Borghi-Silva, Aparecida M. Catai
}

\begin{abstract}
Background: Reduced respiratory muscle endurance (RME) contributes to increased dyspnea upon exertion in patients with cardiovascular disease. Objective: The objective was to characterize ventilatory and metabolic responses during RME tests in post-myocardial infarction patients without respiratory muscle weakness. Method: Twenty-nine subjects were allocated into three groups: recent myocardial infarction group ( $R G, n=9)$, less-recent myocardial infarction group (LRG, $n=10)$, and control group $(\mathrm{CG}, \mathrm{n}=10)$. They underwent two RME tests (incremental and constant pressure) with ventilatory and metabolic analyses. One-way ANOVA and repeated measures one-way ANOVA, both with Tukey post-hoc, were used between groups and within subjects, respectively. Results: Patients from the RG and LRG presented lower metabolic equivalent and ventilatory efficiency than the $\mathrm{CG}$ on the second $(50 \pm 06,50 \pm 5$ vs. $42 \pm 4)$ and third part $(50 \pm 11,51 \pm 10$ vs. $43 \pm 3)$ of the constant pressure RME test and lower metabolic equivalent during the incremental pressure RME test. Additionally, at the peak of the incremental RME test, RG patients had lower oxygen uptake than the CG. Conclusions: Post-myocardial infarction patients present lower ventilatory efficiency during respiratory muscle endurance tests, which appears to explain their inferior performance in these tests even in the presence of lower pressure overload and lower metabolic equivalent.
\end{abstract}

Keywords: cardiac disease; physical therapy; exercise tolerance; respiratory muscles; muscle fatigue.

\section{HOW TO CITE THIS ARTICLE}

Neves LMT, Karsten M, Neves VR, Beltrame T, Borghi-Silva A, Catai AM. Respiratory muscle endurance is limited by lower ventilatory efficiency in post-myocardial infarction patients. Braz J Phys Ther. 2014 Jan-Feb; 18(1):1-8. http://dx.doi.org/10.1590/ S1413-35552012005000134

\section{Introduction}

In most myocardial infarction patients, exercise limitation is manifested as dyspnea or lower limb fatigue $^{1-6}$. The dyspnea is related, among other possibilities, to respiratory muscle strength and endurance ${ }^{7}$, which are expressed as maximal inspiratory pressure (MIP) and respiratory muscle endurance (time [Tlim] or pressure $\left[\mathrm{PTH}_{\mathrm{MAX}}\right]$ ), respectively. Respiratory muscle weakness (MIP $<60 \%$ of predicted values $)^{2,8-10}$ and reduced respiratory muscle endurance (RME) contribute to greater dyspnea upon exertion in patients with chronic diseases, including cardiovascular disease $e^{1,2,8-10}$, affecting their exercise tolerance ${ }^{2,11-14}$.

In any muscle work, ventilatory and metabolic responses are representative of the body's ability to capture, transport, and use oxygen for energy production and eliminate carbon dioxide in order to maintain a relatively normal $\mathrm{pH}^{12}$. Several methodologies are used to evaluate RME. When assessing RME in healthy subjects, the ventilatory and metabolic responses are similar in low-intensity long-duration exercise ${ }^{15}$. We believe that reduced RME performance, proportional to the pressure used, might be a consequence of higher metabolic demand, which indicates greater effort during RME testing.

However, to our knowledge, the magnitude of ventilatory and metabolic responses during RME tests has not been well established in patients with acute or chronic myocardial infarction (MI) without respiratory muscle weakness. We hypothesize that the ventilatory efficiency of post-MI patients without respiratory muscle weakness during RME tests is less than that of healthy subjects.

The aim of the present study was to evaluate ventilatory and metabolic responses during respiratory muscle endurance tests in post-myocardial infarction patients and healthy subjects, all with preserved respiratory muscle strength. 


\section{Method}

This cross-sectional study was approved by the Human Research Ethics Committee of Universidade Federal de São Carlos (UFSCar), São Carlos, SP, Brazil (protocol 353/2009) and conducted in compliance with Declaration of Helsinki guidelines at the Cardiovascular Physical Therapy Laboratory of the Exercise Research Center in the UFSCar Physical Therapy Department. All participants signed an informed consent form.

Post-myocardial infarction patients (35-65 years of age) diagnosed with a single episode of myocardial infarction (Killip I) were recruited and allocated into two groups according to the time since occurrence: recent infarction group ( $R G, n=09$; up to 45 days post$\mathrm{MI})$ and less-recent infarction group (LRG, $\mathrm{n}=10$; at least 6 months post-MI). A control group (CG, $\mathrm{n}=10$ ) was formed from sedentary healthy subjects matched with the other groups for age, body mass, and height. The post-myocardial infarction patients were identified and recruited from the Coronary Unit of the Santa Casa de Misericórdia de São Carlos either directly during admittance (RG) or from the hospital's database (LRG). CG subjects were identified and recruited from the UFSCar School Health Unit (Figure 1). For all subjects, an adequate cognitive level and absence of musculoskeletal, joint, respiratory, neurological or vascular disorders was required for inclusion.

Subjects were excluded if they presented at least one of the following conditions: body mass index $\geq 35 \mathrm{~kg} / \mathrm{m}^{2}$, systolic blood pressure $\geq 140 \mathrm{mmHg}$ and/or diastolic blood pressure $\geq 90 \mathrm{mmHg}$ (at rest), functional capacity $\leq 4$ metabolic equivalents;

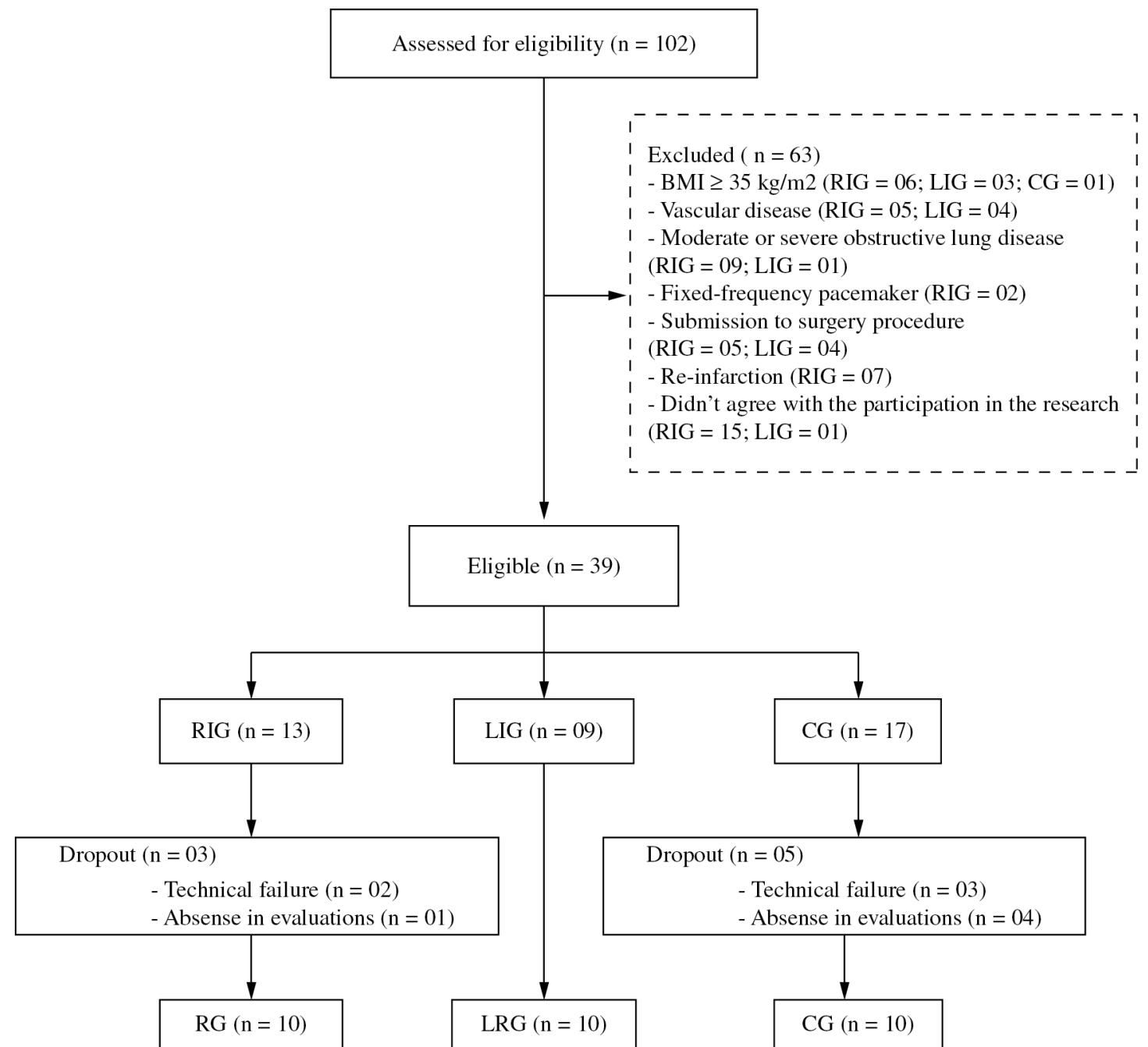

Figure 1. Diagram of sample distribution for the recent post-myocardial infarction group (RG), the less-recent post-myocardial infarction group (LRG), and the control group (CG). 
ST-segment depression $>2 \mathrm{~mm}$, angina pectoris during exercise; exercise-induced decrease in systolic blood pressure $\geq 15 \mathrm{mmHg}$, sustained ventricular arrhythmia, supraventricular arrhythmia that compromised cardiac function, moderate or severe valve disease, a fixed-frequency pacemaker, uncontrolled diabetes, obstructive lung disease, difficulty performing a self-assessment of effort using the Borg scale or respiratory muscle weakness $(\mathrm{MIP}<60 \% \text { of the predicted })^{10,16}$.

\section{Clinical and functional evaluation}

The subjects underwent a) a physical examination of cardiovascular and respiratory parameters at rest, b) a pulmonary function test - slow and forced vital capacity and maximal voluntary ventilation ${ }^{16}$ (CPX-D, Medical Graphics, St Paul, MN, USA), c) a 12-derivation electrocardiogram at rest (Schiller, AT1, Altgasse, Baar, Switzerland) in the supine position, and d) a clinical treadmill exercise test conducted by a cardiologist.

\section{Cardiopulmonary exercise test}

A symptom-limited cardiopulmonary exercise test (CPX) was performed on a treadmill (Master ATL, Inbramed, Porto Alegre, RS, Brazil) using a ramp protocol. A 4-min warm-up period (1.5 $\mathrm{mph}$, no slope) was followed by an incremental increase in walking velocity (over 3 min to achieve maximal walking velocity) and then by $0.5 \%$ increases in elevation every $15 \mathrm{~s}$. Ventilatory and metabolic parameters were monitored and registered breath-by-breath (CPX-D/ BreezeSuite 6.4.1, Medical Graphics, St Paul, MN, USA) and were analyzed after smoothing the data by moving averages of eight respiratory cycles ${ }^{17}$. The electrocardiogram was continuously monitored (Schiller, AT1, Altgasse, Baar, Switzerland), and the heart rate was recorded with a digital telemetry system (Polar ${ }^{\circledR}$ S810i; Polar Electro Oy, Kempele, Oulo, Finland). Every two minutes, blood pressure was assessed and perceived exertion was rated with the Borg scale. The ventilatory method was used by three independent evaluators to identify the anaerobic threshold $(\mathrm{AT})^{17,18}$. Oxygen uptake at this point $\left(\mathrm{VO}_{2 \mathrm{AT}}\right)$ was identified. The highest oxygen uptake observed in the last 30 seconds of exercise was defined as $\mathrm{VO}_{\text {2peak }}{ }^{18}$.

\section{Evaluation of respiratory muscle strength and endurance}

Respiratory muscle strength (RMS) was assessed using a digital pressure transducer (MVD-300,
Globalmed, Porto Alegre, RS, Brazil) ${ }^{19}$. The values observed in the first second after peak pressure were used to define $\mathrm{MIP}^{10}$. RME, ventilatory, and metabolic parameters were assessed and registered breath-bybreath while the patients breathed continuously through the mouthpiece of a linear inspiratory load resistor (Power Breath ${ }^{\circledR}$, IMT Technologies Ltd., Birmingham, UK) connected to a ventilatory and metabolic system (CPX-D/BreezeSuite 6.4.1, Medical Graphics, St Paul, MN, USA).

Incremental and constant pressure tests were employed to assess RME, as previously described ${ }^{14}$. Briefly, the incremental test was based on $3 \mathrm{~min}$ steps and began with a load corresponding to $50 \%$ of the MIP, followed by load increments equivalent to $10 \%$ MIP until the patient failed to achieve the pressure in three consecutive inspirations. The greatest inspiratory pressure sustained at least for 1 min was taken as the measure for inspiratory muscle endurance $\left(\mathrm{Pth}_{\max }\right)^{11,19}$. In the next protocol, a constant load $\left(80 \%\right.$ of the Pth max $_{\text {mas }}$ was employed. The time elapsed to task failure was defined as respiratory muscle endurance time (Tlim).

\section{Statistical analysis}

The data were analyzed using Statistica 7 (StatSoft Inc., Tulsa, OK, USA). Based on the results of a pilot study $(n=4)$, we estimated that a sample size of six individuals in each group would be sufficient to detect a 10-point difference in ventilatory efficiency (statistical power of $80 \%$ ). The level of significance was set at 5\%. Normally-distributed data (ShapiroWilk test) are presented as mean \pm SD; Non-normally distributed data are expressed as median (minimum and maximum values). One-way ANOVA with Tukey post-hoc and repeated measures one-way ANOVA with Tukey post-hoc were used to analyze data between groups and within subjects, respectively.

\section{Results}

\section{Clinical and functional evaluation}

The sample consisted of middle-aged men without respiratory muscle weakness and with similar anthropometric characteristics between groups. For all groups, spirometric values were within the range predicted for the Brazilian population, with no difference among groups ${ }^{20}$. In the post-myocardial infarction groups, the mean time elapsed between infarction and inclusion in the study was 33 (range: 16 to 45 ) days in the RG and 702 (range: 219 to 923) days in the LRG. Most had an anterior or inferior 
infarction (53\%) with bi-arterial involvement (48\%) and had undergone percutaneous transluminal coronary angioplasty (95\%). All RG and LRG subjects had preserved ventricular function with a left ventricular ejection fraction greater than $50 \%$, according to ventriculography.

\section{Cardiopulmonary exercise test}

During the cardiopulmonary exercise test, $\mathrm{VO}_{2 \mathrm{AT}}$ and $\mathrm{VO}_{2 \text { peak }}$ (absolute and corrected for body mass) were higher in the CG than in the RG or LRG (Table 1).

\section{Ventilatory and metabolic responses during RME protocols}

The majority of the ventilatory variables (tidal volume, respiratory rate, inspiratory time, expiratory time, inspiratory time relative to total respiratory cycle, minute volume, and partial $\mathrm{CO}_{2}$ pressure at the end of expiration) and metabolic variables $\left(\mathrm{CO}_{2}\right.$ output and respiratory exchange ratio) remained constant during the incremental and constant pressure tests and did not differ among groups. At 70 and $80 \%$ of MIP during the incremental pressure test and during the second and third parts of the constant pressure test, the RG had lower MET and higher $\mathrm{VE} / \mathrm{VCO}_{2}$ than the CG. At $90 \%$ MIP during the incremental pressure test, the $\mathrm{RG}$ had lower $\mathrm{VO}_{2}$ and MET than the CG (Tables 2 and 3).

Furthermore, at all stages of respiratory endurance tests the $\mathrm{RG}$ requires a higher percentage of $\mathrm{VO}_{2 \text { peak }}$ ( $5 \%$ above compared to $\mathrm{CG}$ ) to maintain a lower pressure and product pressure-time ${ }^{14}$ (Figure 2). This behavior was not presented at the higher stage $(90 \%$ MIP) of incremental pressure test.

\section{Discussion}

The main results of this descriptive, cross-sectional study provide new evidence about the source of reduced RME in recent post-MI patients without inspiratory muscle weakness. The reduction seems to be due to the lower ventilatory efficiency observed from the middle to the final part of the protocols, even when they experienced lower pressure overload than sedentary healthy subjects. The sample consisted of middle-aged men with similar anthropometric characteristics and similar clinical characteristics between post-MI groups. Only subjects with normal respiratory function were included in the present study in order to reduce the influence of obstructive or restrictive diseases on RME performance. Impaired exercise tolerance is a characteristic of cardiac patients who have undergone angioplasty, although

Table 1. Anthropometric characteristics and cardiopulmonary capacity of the recent infarction group (RG), the less-recent infarction group (LRG) and the control group (CG).

$\begin{array}{llll}\text { Values } & \text { RG }(n=9) & \text { LRG }(n=10) & \text { pG }(n=10)\end{array}$

Anthropometric

$\begin{array}{lcccr}\text { Age (years) } & 48 \pm 8 & 51 \pm 6 & 49 \pm 9 & 0.45 \\ \text { Body mass }(\mathrm{kg}) & 81 \pm 11 & 83 \pm 15 & 79 \pm 10 & 0.73 \\ \text { Height }(\mathrm{m}) & 1.7 \pm 0.1 & 1.7 \pm 0.1 & 1.8 \pm 0.1 & 0.89 \\ \mathrm{BMI}\left(\mathrm{kg} / \mathrm{m}^{2}\right) & 28 \pm 4 & 29 \pm 4 & 25 \pm 3 & 0.10 \\ \text { MIP }\left(\mathrm{cmH}_{2} \mathrm{O}\right) & 87 \pm 21 & 101 \pm 12 & 106 \pm 26 & 0.09 \\ \text { MIP }(\% \text { predicted }) & 71 \pm 18 & 87 \pm 23 & 84 \pm 20 & 0.06\end{array}$

CPX

$\begin{array}{lcccr}\mathrm{VO}_{2 \mathrm{AT}}\left(\mathrm{mL} \cdot \mathrm{min}^{-1}\right) & 1203 \pm 171 & 1426 \pm 298 & 1601 \pm 262^{¥} & <0.01 \\ \mathrm{VO}_{2 \mathrm{AT}}\left(\mathrm{mL} \cdot \mathrm{kg}^{-1} \cdot \mathrm{min}^{-1}\right) & 15 \pm 3 & 18 \pm 4 & 21 \pm 4^{¥} & <0.01 \\ \mathrm{VO}_{2 \text { peak }}\left(\mathrm{mL} \cdot \mathrm{min}^{-1}\right) & 2030 \pm 446 & 2268 \pm 391 & 2931 \pm 341^{\#} & <0.01 \\ \mathrm{VO}_{2 \text { peak }}\left(\mathrm{mL} \cdot \mathrm{kg}^{-1} \cdot \mathrm{min}^{-1}\right) & 26 \pm 6 & 28 \pm 6 & 38 \pm 4^{\#} & <0.01 \\ \text { Dyspnea }(\mathrm{CR} 10) & 6.4 \pm 2.8 & 7.3 \pm 2.3 & 6.3 \pm 2.6 & 0.72 \\ \text { Fatigue }(\mathrm{CR} 10) & 5.0 \pm 3.2 & 6.2 \pm 2.9 & 4.9 \pm 3.4 & 0.70\end{array}$

BMI: body mass index; MIP: maximal inspiratory pressure; CPX: cardiopulmonary exercise test; VO $\mathrm{V}_{\mathrm{AT}}$ : anaerobic threshold oxygen uptake $\mathrm{VO}_{2 \text { peak }}$ : peak oxygen uptake; $\mathrm{VO}_{2 \mathrm{AT}}$ : anaerobic threshold oxygen uptake; ${ }^{*} \mathrm{p}<0.05$ compared to RG with one-way ANOVA (Tukey post-hoc); ${ }^{\#} \mathrm{p}<0.05$ compared to RG and LRG with one-way ANOVA (Tukey post-hoc). Part of the data was originally published in Neves et al.15, used with permission (2951481234155). 


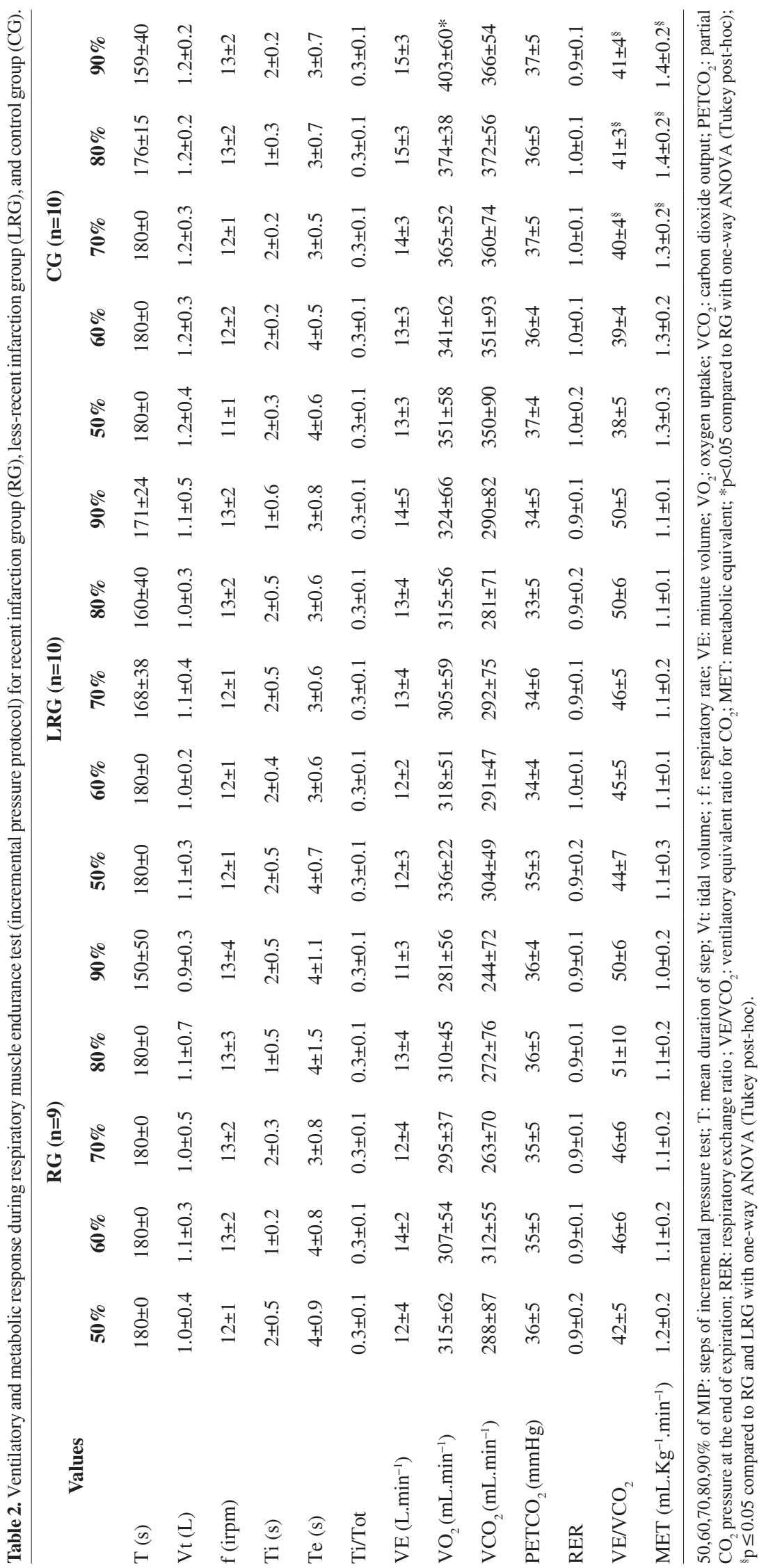


Table 3. Ventilatory and metabolic response during respiratory muscle endurance test (constant pressure protocol) for the recent infarction group (RG), the less-recent infarction group (LRG), and the control group (CG).

\begin{tabular}{|c|c|c|c|c|c|c|c|c|c|}
\hline \multirow[t]{2}{*}{ Values } & \multicolumn{3}{|c|}{ RIG (n=9) } & \multicolumn{3}{|c|}{ LRG (n=10) } & \multicolumn{3}{|c|}{ CG $(n=10)$} \\
\hline & I & II & III & I & II & III & $\mathbf{I}$ & II & III \\
\hline $\mathrm{Vt}(\mathrm{L})$ & $0.9 \pm 0.3$ & $0.8 \pm 0.2$ & $0.8 \pm 0.1$ & $0.9 \pm 0.2$ & $0.9 \pm 0.3$ & $0.9 \pm 0.3$ & $1.1 \pm 0.3$ & $1.3 \pm 0.6$ & $1.3 \pm 0.6$ \\
\hline f (irpm) & $12 \pm 2$ & $13 \pm 2$ & $14 \pm 2$ & $13 \pm 1$ & $14 \pm 1$ & $14 \pm 2$ & $12 \pm 1$ & $12 \pm 2$ & $13 \pm 2$ \\
\hline $\mathrm{Ti}(\mathrm{s})$ & $2 \pm 0.3$ & $2 \pm 0.3$ & $2 \pm 0.4$ & $2 \pm 0.5$ & $1 \pm 0.5$ & $1 \pm 0.5$ & $2 \pm 0.7$ & $2 \pm 0.9$ & $2 \pm 0.7$ \\
\hline $\mathrm{Te}(\mathrm{s})$ & $3 \pm 0.8$ & $3 \pm 0.6$ & $3 \pm 0.1$ & $3 \pm 0.4$ & $3 \pm 0.7$ & $3 \pm 0.6$ & $3 \pm 0.6$ & $3 \pm 0.8$ & $3 \pm 0.5$ \\
\hline Ti/Tot & $0.3 \pm 0.1$ & $0.4 \pm 0.1$ & $0.3 \pm 0.1$ & $0.3 \pm 0.1$ & $0.3 \pm 0.1$ & $0.3 \pm 0.1$ & $0.3 \pm 0.1$ & $0.3 \pm 0.1$ & $0.3 \pm 0.1$ \\
\hline VE $\left(\mathrm{L} \cdot \mathrm{min}^{-1}\right)$ & $10 \pm 2$ & $11 \pm 2$ & $11 \pm 3$ & $11 \pm 3$ & $13 \pm 5$ & $12 \pm 4$ & $13 \pm 3$ & $14 \pm 6$ & $17 \pm 8$ \\
\hline $\mathrm{VO}_{2}\left(\mathrm{~mL} \cdot \mathrm{min}^{-1}\right)$ & $308 \pm 50$ & $293 \pm 28$ & $279 \pm 26$ & $313 \pm 40$ & $306 \pm 49$ & $296 \pm 63$ & $354 \pm 67$ & $336 \pm 45$ & $350 \pm 62$ \\
\hline $\mathrm{VCO}_{2}\left(\mathrm{~mL} \cdot \mathrm{min}^{-1}\right)$ & $258 \pm 48$ & $261 \pm 30$ & $245 \pm 39$ & $253 \pm 53$ & $273 \pm 64$ & $255 \pm 58$ & $326 \pm 60$ & $318 \pm 51$ & $329 \pm 77$ \\
\hline $\mathrm{PETCO}_{2}(\mathrm{mmHg})$ & $38 \pm 3$ & $37 \pm 3$ & $37 \pm 4$ & $36 \pm 4$ & $35 \pm 6$ & $35 \pm 5$ & $35 \pm 5$ & $33 \pm 7$ & $31 \pm 8$ \\
\hline RER & $0.8 \pm 0.1$ & $0.9 \pm 0.1$ & $0.9 \pm 0.1$ & $0.8 \pm 0.1$ & $0.9 \pm 0.1$ & $0.9 \pm 0.1$ & $0.9 \pm 0.2$ & $1.0 \pm 0.2$ & $0.9 \pm 0.2$ \\
\hline $\mathrm{VE} / \mathrm{VCO}_{2}$ & $41 \pm 7$ & $50 \pm 6$ & $50 \pm 11$ & $41 \pm 7$ & $50 \pm 5$ & $51 \pm 10$ & $41 \pm 5$ & $42 \pm 4^{\S}$ & $43 \pm 3^{\S}$ \\
\hline $\operatorname{MET}\left(\mathrm{mL} \cdot \mathrm{kg}^{-1} \cdot \mathrm{min}^{-1}\right)$ & $1.1 \pm 0.2$ & $1.0 \pm 0.1$ & $1.0 \pm 0.1$ & $1.1 \pm 0.1$ & $1.1 \pm 0.1$ & $1.0 \pm 0.2$ & $1.3 \pm 0.2$ & $1.2 \pm 0.2^{\S}$ & $1.3 \pm 0.2^{\S}$ \\
\hline
\end{tabular}

I, II and III: constant pressure time (initial, middle and end); Vt: tidal volume; f: respiratory frequency ; Ti: inspiratory time; Te: expiratory time; Ti/Ttot: inspiratory time relative to total respiratory cycle; $\mathrm{VE}$ : minute volume; $\mathrm{VO}_{2}$ : oxygen uptake; $\mathrm{VCO}_{2}$ : carbon dioxide output; PETCO; partial $\mathrm{CO}_{2}$ pressure at the end of expiration; RER: respiratory exchange ratio; VE/VCO equivalent; ${ }^{\S} \mathrm{p} \leq 0.05$ compared to RG and LRG with one-way ANOVA (Tukey post-hoc).
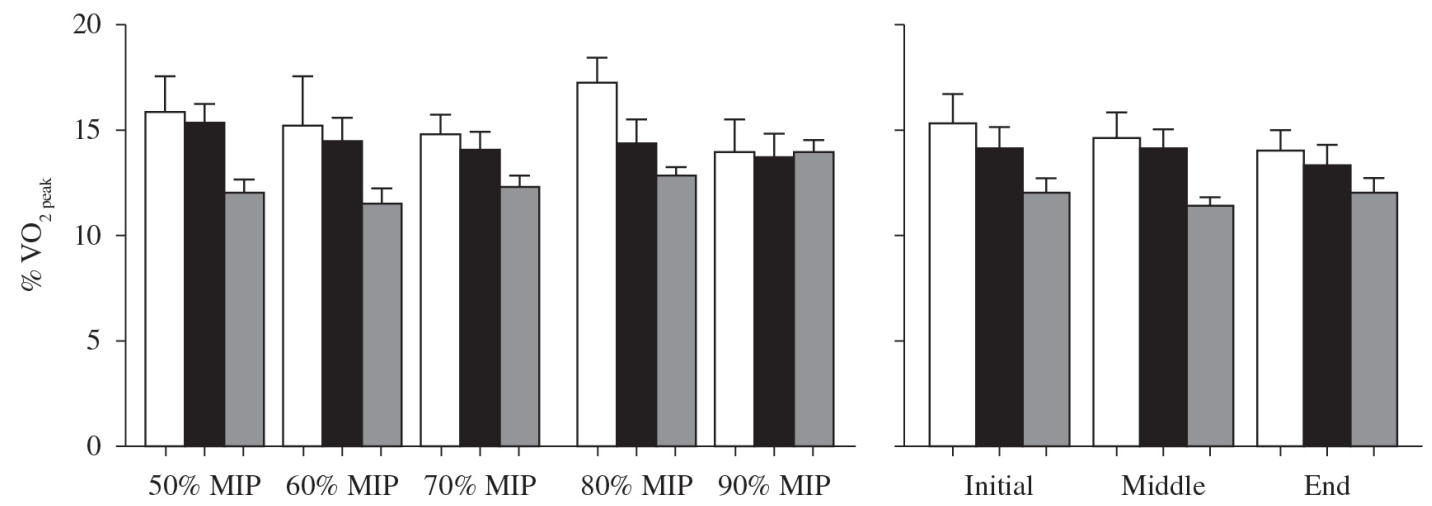

Figure 2. Illustration of the percentage of oxygen uptake at peak exercise $\left(\% \mathrm{VO}_{2 \text { peak }}\right)$ during the incremental and constant pressure protocol endurance tests for the recent infarction group (RG-white), the less-recent infarction group (LRG-black), and the control group (CG-gray).

their exercise tolerance tends to increase with exercise programs $^{21-23}$. The exercise tolerance of the post-MI sample was greater than that found in other studies of cardiovascular disease ${ }^{11,24}$. This difference is likely due to the preserved left ventricular ejection fraction observed in the present study and also to the fact that our sample was younger and had a lower body mass index and fewer comorbidities.

The low variation in ventilatory and metabolic values in both incremental and constant pressure RME tests may reflect a low and almost constant work rate ${ }^{24}$. Analyzing other similar studies ${ }^{22,25-31}$, we inferred that the RME assessment methods involved are the most probable contributors to the variation in results. The differences include the type of applied load (elastic or resistive), the mode of load application (constant or incremental), the degree of motivation and the respiratory pattern (free or controlled) ${ }^{26}$. The assessment of oxygen uptake percentage at peak exercise in the RME tests was an attempt to classify the intensity level of the achieved work rate, and we observed similar values between groups. However, the fact that the RG performed the RME tests with a $20 \%$ lower pressure than the CG could indicate that the RME tests represented a proportionally higher intensity for the RG. The consensus for respiratory tests is that the greater the pressure imposed with higher tidal volume, inspiratory time or inspiratory 
flow, the lower the test tolerance is ${ }^{32}$. Furthermore, the influence of other factors such as gender, age, and height on RME test performance is poorly understood $^{13}$. We observed that in post-MI patients, lower ventilatory efficiency was not compensated with superficial breathing and a consequent increase in respiratory rate ${ }^{28}$ but, rather, increased recruitment and contraction of respiratory muscles was the means of generating enough inspiratory flow to deal with the imposed pressure ${ }^{14}$. Considering that the variables were kept constant, other dynamic factors such as the recruitment of respiratory muscles and changes in airway resistance ${ }^{28}$ appear to influence respiratory muscle function and interfere with RME test performance in post-MI patients.

\section{Study limitations}

In this small descriptive cross-sectional study, we showed that there is lower ventilatory efficiency in the second part of test protocols in recent infarction patients without respiratory muscle weakness, even in the presence of lower pressure overload. Our findings were limited by the absence of a breath-by-breath respiratory muscle strength evaluation and patient follow-up over the recent and less recent myocardial infarction periods. Another limitation is related to the lack of predicted values for respiratory muscle endurance in each population.

\section{Clinical implications}

Our findings indicate that the reduced RME with increased respiratory effort observed in recent postMI patients during RME tests could be influenced by their lower ventilatory efficiency. This is the first time that a possible limiting factor for dynamic exercise capacity in post-myocardial infarction has been associated with ventilatory efficiency due to a respiratory muscle component. Our results also raise the question of whether the addition of inspiratory muscle training in cardiac rehabilitation can improve RME performance and ventilatory efficiency in recent post-MI patients without respiratory muscle weakness.

\section{- Conclusion}

In this descriptive, cross-sectional study with recent and less-recent post-MI patients without inspiratory muscles weakness, the lower ventilatory efficiency observed during respiratory muscle endurance tests appears to clarify the inferior performance on these tests, even in the presence of lower pressure overload.

\section{References}

1. Morrison NJ, Fairbarn MS, Pardy RL. The effect of breathing frequency on inspiratory muscle endurance during incremental threshold loading. Chest. 1989;96:858. PMid:2736996. http://dx.doi.org/10.1378/chest.96.1.85

2. Jones NL, Killian KJ. Mechanisms of disease: Exercise limitation in health and disease. N Engl J Med. 2000;342(9):632-41. http://dx.doi.org/10.1056/ NEJM200008313430907

3. Caroci AS, Lareau SC, Linda L. Descriptors of dyspnea by patients with chronic obstructive pulmonary disease versus congestive heart failure. Heart Lung. 2004;33:10210. PMid:15024375. http://dx.doi.org/10.1016/j. hrtlng.2003.11.004

4. Hamilton AL, Killian KJ, Summers E, Jones NL. Muscle strength, symptom intensity, and exercise capacity in patients with cardiorespiratory disorders. Crit Care Med. 1995;152:2021-31. PMid:8520771. http://dx.doi. org/10.1164/ajrccm.152.6.8520771

5. Stendardi L, Grazzini M, Gigliotti F, Lotti P, Scano G. Dyspnea and leg effort during exercise. Respir Med. 2005;99:933-42. PMid:15950133. http://dx.doi. org/10.1016/j.rmed.2005.02.005

6. Ambrosino N, Serradori M. Determining the cause of dyspnoea: linguistic and biological descriptors. Chron Respir Dis. 2006;3:117-22. http://dx.doi. org/10.1191/1479972306cd110ra

7. Reid WD, Clarke TJ, Wallace AM. Respiratory muscle injury: evidence to date and potential mechamisms. Can J Apl Physiol. 2001;26:356-87. http://dx.doi.org/10.1139/ h01-023

8. Wastford ML, Murphy A J, Pine MJ. The effects of age in on respiratory muscle function and performance in older adults. J Sci Med Sport. 2007;10:36-44. PMid:16814604. http://dx.doi.org/10.1016/j.jsams.2006.05.002

9. Ribeiro JP, Chiappa GR, Callegaro CC. The contribution of inspiratory muscles function to exercise limitation in heart failure: pathophysiological mechanisms. Rev Bras Fisioter. 2012;16(4):261-267. PMid:22801449. http:// dx.doi.org/10.1590/S1413-35552012005000034

10. Hautmann H, Hefele S, Schotlen K, Huber RM. Maximal inspiratory mouth pressures (PIMAX) in healthy subjects - what is lower limit of normal? Respir Med. 2000;94:689-93. PMid:10926341. http://dx.doi. org/10.1053/rmed.2000.0802

11. Dall'Ago P, Chiappa GR, Guths H, Stein R, Ribeiro JP. Inspiratory muscle training in patients with heart failure and inspiratory muscle weakness: a randomized trial. J Am Coll Cardiol. 2006 Feb 21;47(4):757-63. PMid:16487841.

12. Wasserman K, Hansen JE, Sue DY, Whipp BJ, Casaburi R. Principles of exercise testing and interpretation. Philadelphia: Lea \& Febiger; 1999.

13. Windisch W, Hennings E, Sorichter S, Hamm H, Criée CP. Peak or plateau maximal inspiratory mouth pressure: which is best? Eur Respir J. 2004;23:708-13. PMid:15176684. http://dx.doi.org/10.1183/09031936.0 4.00136104 
14. Neves LMT, Karsten M, Neves VR, Beltrame T, Borghi-Silva A, Catai AM. Relationship between inspiratory muscle capacity and peak exercise tolerance in post-myocardial infarction patients. Heart Lung. 2012;41(2):137-45. PMid:22177761. http://dx.doi. org/10.1016/j.hrtlng.2011.07.010

15. Neves LMT, Karsten M, Borghi-Silva A, Catai AM. Comportamento ventilatório e metabólico na avaliação da endurance dos músculos inspiratórios de indivíduos pós-infarto do miocárdio. Rev Bras Fisioter. 2010;14 (Supl.1):449.

16. Pereira CAC. Espirometria. Diretrizes para testes de função pulmonar. J Bras Pneumol. 2002;28(3):S1-82.

17. Balady GJ, Arena R, Sietsema K, Myers J, Coke L, Fletcher GF, et al. Clinician's Guide to cardiopulmonary exercise testing in adults: a scientific statement from the American Heart Association. Circulation. 2010;122:191225. PMid:20585013. http://dx.doi.org/10.1161/ CIR.0b013e3181e52e69

18. Higa MN, Silva E, Neves VFC, Catai AM, Gallo L Jr, Sá MFS. Comparison of anaerobic threshold determined by visual and mathematical methods in healthy women. Braz J Med Biol Res. 2007;40:501-8. PMid:17401493. http:// dx.doi.org/10.1590/S0100-879X2007000400008

19. American Thoracic Society/European Respiratory Society. ATS/ERS Statement on respiratory muscle testing. Am J Resp Crit Care Med. 2002;166:518-624. PMid:12186831. http://dx.doi.org/10.1164/rccm.166.4.518

20. Neder JA, Andreoni S, Lerario MC, Nery LE. Reference values for lung function tests. II. Maximal respiratory pressures and voluntary ventilation. Braz J Med Biol Res. 1999;32:719-27. PMid:10412550. http://dx.doi. org/10.1590/S0100-879X1999000600007

21. Gassner LA, Dunn S, Piller N. Aerobic exercise and the post myocardial infarction patient: A review of the literature. Heart Lung. 2003;32:258-65. http://dx.doi. org/10.1016/S0147-9563(03)00039-6

22. Jones GL, Killian KJ, Summers E, Jones NJ. Inspiratory muscle forces and endurance in maximum resistive loading. J Appl Physiol. 1985;58:1608-15. PMid:3997725.

23. Ainsworth BE, Haskell WL, Leon AS, Jacobs DR, Montoye $\mathrm{JH}$, Sallis JF, et al. Compendium of physical activities: classification of energy costs of human physical activities. Med Sci Sports Exerc. 1993;25(1):71-80. PMid:8292105. http://dx.doi.org/10.1249/00005768-199301000-00011

24. Chiappa GR, Roseguini BT, Vieira PJC, Alves CN, Tavares A, Winkelmann ER, et al. Inspiratory muscle training improves blood flow to resting and exercising limbs in patients with chronic heart failure. J Am Coll Cardiol. 2008;51(17):1663-71. PMid:18436118. http:// dx.doi.org/10.1016/j.jacc.2007.12.045

25. Martyn JB, Moreno RH, Paré PD, Pardy RL. Measurement of inspiratory muscle performance with threshold loading. Am Rev Respir Dis. 1987;135:919-23. PMid:3565939.

26. Eastwood PR, Hillman DR, Finucane KF. Inspiratory muscles performance in endurance athletes and sedentary subjects. Respirology. 2001;6:95-104. PMid:11422888. http://dx.doi.org/10.1046/j.1440-1843.2001.00314.x

27. Freedman S, Campbell EJM. The ability of normal subjects to tolerate added inspiratory loads. Respir Physiol. 1970;10:213-35. http://dx.doi. org/10.1016/0034-5687(70)90084-8

28. Jederlinic P, Muspratt JA, Miller MJ. Inspiratory muscle training in clinical practice: physiologic conditioning or habituation to suffocation? Chest. 1984;86:870-3. PMid:6499549. http://dx.doi.org/10.1378/chest.86.6.870

29. McElvaney G, Fairban MS, Wilcox PG, Pardy RL. Comparison of two-minute incremental threshold loading and maximal loading as measures of respiratory muscles endurance. Chest. 1989;96:557-63. PMid:2766814. http:// dx.doi.org/10.1378/chest.96.3.557

30. Yan S, Sliwinski P, Gauthier AP, Lichros I, Zakynthinos S, Macklem PT. Effect of global inspiratory muscle fatigue on ventilatory and respiratory muscle responses to $\mathrm{CO}_{2}$. J Appl Physiol. 1993;75(3):1371-7. PMid:8226553.

31. Clanton TL, Diaz PT. Clinical assessment of the respiratory muscles. Phys Ther. 1995;75(11):983-95. PMid:7480128.

32. Callegaro CC, Martinez D, Ribeiro PAB, Brod M, Ribeiro JP. Augmented peripheral chemoreflex in patients with heart failure and inspiratory muscle weakness. Respir Physiol Neurobiol. 2010;171:31-5. PMid:20096381. http://dx.doi.org/10.1016/j.resp.2010.01.009

\section{Correspondence}

\section{Aparecida M. Catai}

Universidade Federal de São Carlos

Departamento de Fisioterapia

Laboratório de Fisioterapia Cardiovascular

Rodovia Washington Luís, km 235

CEP 13565-905, São Carlos, SP, Brazil

e-mail: mcatai@ufscar.br 